\title{
Introducing a national health insurance system in South Africa: A general practitioner's bottom-up approach to costing
}

\author{
Shabir Moosa, John M Luiz, Teresa Carmichael
}

Background. The introduction of national health insurance (NHI) is an important debate in South Africa, with affordability and institutional capacity being the key issues. NHI costing has been dominated by estimates of exorbitant cost. However, capitation is not only a different payment system but also a different service delivery model, and as a result there are opportunities for risk management and efficiencies.

Objective. This study explores how private general practitioners (GPs) may choose to embrace these service delivery concepts and deal with the cost implications to meet $\mathrm{NHI}$ requirements.

Methods. Data were collected from 598 solo private GPs through a self-administered online questionnaire survey across South Africa.
Results. In spite of poor engagement with the public sector, and some challenges in costing and organisation, GPs appear to have an affordable and pro-active response to NHI capitation costing and fee setting. On average, they would accept a minimum global fee of R4.03 million to look after a population of 10000 people for personal healthcare services.

Conclusion. At a total cost to the country of R16.9 billion, government could affordably use GPs to develop the primary healthcare part of NHI to cover the entire South African uninsured population. It is anticipated that a similar approach would be successful in other developing countries.

S Afr Med J 2012;102(10):794-797. DOI:10.7196/SAMJ.6072
Considerable attention has been given to developing a national health insurance (NHI) system in South Africa (SA), with a strong emphasis on including private general practitioners (GPs) to deliver primary healthcare (PHC). This system switch is based on a shift from a fee-for-service payment system (where the patient pays for each service, starting with the consultation) to capitation payment. ${ }^{1}$ Such a comprehensive switch in health systems is ambitious, especially for an emerging country, but also resonates with debates in the industrialised world around escalating healthcare costs and the apparent unaffordability of comprehensive health insurance, notably in the USA. ${ }^{2}$

The NHI proposed for SA is a government-managed central buyer of healthcare services that aims to improve access to healthcare. It would be introduced over 14 years, starting with a pilot programme in 2012. ${ }^{1}$ Membership would be compulsory for all South Africans and legal permanent residents, and existing medical schemes would continue alongside the NHI. The NHI has been contentious, with wildly fluctuating estimates of its costs. The government public health service spend in 2011/2012 was R121 billion for $85 \%$ of the population. The government model in the NHI indicates that resource requirements will increase from R128 billion in 2012 to R255 billion in 2025 . The media reflexively expect that the R85 billion private medical schemes spent in 2010 on $15 \%$ of the population will mean an NHI cost of R567 billion. GP care would comprise R42 billion (assuming the current 7.4\% GP share of private

Department of Family Medicine, Faculty of Health Sciences, University of the Witwatersrand, Johannesburg

Shabir Moosa, MB BCh, MMed, MBA

Graduate School of Business, University of Cape Town

John M Luiz, BCom Hons, MCom, PhD

Wits Business School, University of the Witwatersrand, Johannesburg Teresa Carmichael, BSc Hons, MM (HR), PhD

Corresponding author: J M Luiz (john.luiz@gsb.uct.ac.za) medical scheme spend) for the $85 \%$ of the population. There are other estimates of R187 billion for ambulatory care or R176 billion for basic prescribed care. ${ }^{3}$

We aimed to evaluate the views of private solo GPs on general practice, capitation and costs in an NHI system in SA, to fill a gap in developing a more quantifiable assessment of risk-taking among GPs and cost estimates for the NHI.

\section{Methods}

Quantitative and qualitative data were gathered, via e-mail linking to a self-administered online questionnaire. The population was all private GPs $(N=11552)$ licensed by the Board of Healthcare Funders (BHF) to practise privately in SA. E-mails were sent in May 2011 to the 8721 GPs in this database with e-mails. The 598 respondents $(6.7 \%)$ came from all of SA's nine provinces (Table 1). Non-responders were contacted with an SMS and two e-mail reminders.

In the questionnaire a specific proposal was put regarding the provision of personal-curative and preventive-promotive healthcare to a proposed 10000 population, with an expected utilisation rate of three visits per person per annum. The risk pool and potential practice list of 10000 was chosen as it enables GPs to explore team-based care to deal with higher utilisation: big enough for economies and small enough to ensure quality care by the team. Actuarially any random pool of 1000 people would have the same primary care risk as any other 1000 people. This grows to 20000 people to adequately pool hospital care risk. ${ }^{4}$ The current utilisation of metro public health services, as per district health information systems, is two visits per annum. An assumption of three was made. GPs were required to provide information relating to current and expected (under the NHI) staffing and operational costs and to state the minimum global fee they would accept for the specific proposal. Open questions sought data on risks and risk management. Reliability was achieved with the standard data collection method of an online questionnaire. Stability of the standard instrument achieved consistent results despite changes in context. Internal consistency was achieved through the homogeneity of scale items. 
Table 1. Demographic characteristics of respondents

\begin{tabular}{|c|c|c|c|c|c|}
\hline Variable & Segments & $\%$ & Mean & Median & Mode \\
\hline \multirow[t]{2}{*}{ Gender } & Female & 25.1 & & & \\
\hline & Male & 74.9 & & & \\
\hline \multirow[t]{6}{*}{ Age (yrs) } & $25-34$ & 16 & 45.8 & 53 & 45 \\
\hline & $35-44$ & 32 & & & \\
\hline & $45-54$ & 30 & & & \\
\hline & $55-64$ & 16 & & & \\
\hline & $65-74$ & 5 & & & \\
\hline & $75-84$ & 1 & & & \\
\hline \multirow[t]{4}{*}{ Race } & Black & 26.5 & & & \\
\hline & Coloured & 3.2 & & & \\
\hline & Asian & 30.5 & & & \\
\hline & White & 39.8 & & & \\
\hline \multirow[t]{5}{*}{ Area } & City centre & 9.3 & & & \\
\hline & City suburb & 35.9 & & & \\
\hline & Rural & 8.4 & & & \\
\hline & Town & 30.7 & & & \\
\hline & Township & 15.6 & & & \\
\hline \multirow[t]{6}{*}{ Experience (yrs) } & $1-9$ & 31.7 & 16.5 & 29 & 20 \\
\hline & $10-19$ & 28.8 & & & \\
\hline & $20-29$ & 24.7 & & & \\
\hline & $30-39$ & 11.5 & & & \\
\hline & $40-49$ & 2.6 & & & \\
\hline & $50-59$ & 0.7 & & & \\
\hline
\end{tabular}

\section{Results and discussion} Current general practice and systems

GPs appear optimistic about the state of their practices, with $70 \%$ indicating practice growth in the past 4 years and 65\% expecting continued growth in the next 4 years. This optimism prevails despite the declining GP share of medical schemes payments (from 16\% in 2000 to $7.4 \%$ in 2010), and the uncertainty of NHI proposals. ${ }^{5}$

In our sample medical aid schemes dominate GP practices, constituting almost $60 \%$ of practice. Capitation is uncommon, with $60.6 \%$ of respondents indicating that $0-10 \%$ of their patients are capitated. However, $25 \%$ of GPs have more than $20 \%$ of their patients in a capitation plan, which suggests that they are already playing a prominent role in capitation.

Our sample average GP sees 22 patients daily, charges R236.90 for a consultation, and works for 24 days a month or 288 days a year The average annual turnover is R1 500 998, and the expenditure is R701 717 (46.75\% of turnover); staffing expenditure is R197 323 (28.12\% of total expenses), and operational expenditure R206 164 (29.38\% of total expenses). The remaining R298 230 per annum (37\% of total expenses) is assumed to be income tax, which, while part of total expenses, is not commonly viewed by small businesses as an operating expense. A GP seeing 4 patients an hour and working an 8-hour day would be able to see 32 patients, with capacity for 10 extra patients per day.

The average GP's current staffing structure, with just her/himself and $1-2$ administrative staff, is very simple. Internationally more GPs are shifting into practice groups and away from stand-alone small operations, as the health sector becomes more sophisticated. ${ }^{6}$
Despite their concern about risks such as high utilisation rates and uncertainty around government contracting, their key strategy to reduce risk was to improve their management capacity and employ additional staff. Many GPs were averse to considering partnerships.

\section{Understanding and costing of NHI}

GPs were mostly ambivalent about NHI, with $47 \%$ taking a neutral stance; $21.5 \%$ supported it and $32.5 \%$ did not. GPs appear uncomfortable with the lack of clarity and control of risks with NHI. A few respondents made statements about leaving SA. Some cynicism was mostly related to the specific NHI capitation proposal in the research. Of solo GPs, $24.2 \%$ rated their own understanding of capitation as very poor to poor whereas $75.8 \%$ rated their understanding as fair to very good.

A concern is that GPs appear to underestimate the additional staffing costs required in the NHI capitation proposal. They chose to add the equivalent of 1.4 PHC nurse/doctor, 1.6 nurse and 1.3 administrative staff to their current staff, who together with the GP were expecting to see the proposed 120 patients a day. When considering the additional staff cost of R197 323 per annum, their proposals were a mean of $86 \%$ additional costs, which were very low for the staff chosen. Department of Health scales would cost 1.3 level 8 administrative staff at R340 601, 1.6 grade 2 professional nurse at R414 963, and 1.4 grade 2 clinical nurse practitioner at R546 220 per annum. Their proposed new staffing would add $\pm \mathrm{R} 1.30$ million (560\%) to their current staffing cost - a far cry from their estimated $86 \%$ more. GPs therefore need to give more attention to staffing costs. 
Although GPs appeared to want to employ and build teams, they also seemed to expect to see the patients themselves. The international trend is to form practice groups by adding nurse practitioners, which would involve a change of the GP's role from provider to co-ordinator. ${ }^{6}$ Half the doctors chose to appoint another doctor in addition to themselves, rather than a PHC nurse. This may be due to caution regarding the perceived competencies of PHC nurses. Patients may also possibly demand to see doctors and not nurses.

The GPs' minimum global fee per year to accept looking after a total population of 10000 people for curative, preventive and promotive services was a mean of R4.03 million, with bimodal peaks at R2 million and R5 million. Of the respondents over $30 \%$ priced the minimum global fee per year at R2 million and below. GPs appear to make an average after-tax income of R799 282 with their current expenses. Making generous adjustments to expenses, total expenses would be R2 209665 (Table 2). Table 3 shows changes to current GP after-tax income when examining the three scenarios of the average fee of R4.03 million and the bimodal peaks of R2 million and R5 million.

The cost of PHC expenditure (medicines, investigations, maternity obstetric units and allied healthcare services, but excluding hospitals) in metro districts for 2008/2009 in SA was R415 per capita or R4.15 million per 10 000, ranging from R220 to R505 per capita. Drawing comparisons by removing the $30 \%$ for medicines and investigations and the $7 \%$ for MOUs and increasing the utilisation by $50 \%$, the metro districts cost would therefore be R392 per capita or R3.92 million per 10000 population. The average global fee of R403 per capita or R4.03 million per 10000 population by GPs compares well with R11 difference per person per year. With the public service health budget in 2011/12 at R121 billion, provision of PHC by GPs appears to be affordable. At R4.03 million per 10000 people, the total cost for such care for the uninsured SA population of 42.5 million people would be R17.1 billion. While excluding medicines, investigations and possible adjustments for utilisation, age, gender and rural location, such costs are well below the private sector estimates of R187 billion for ambulatory care or the R176 billion for basic prescribed care. ${ }^{3}$ Private sector models are derived from current fee-for-service medical aid data and do not take into account the opportunity for doctors to manage healthcare differently given a capitated environment.

\section{Risk management}

The major themes to the open-ended questions regarding risk affecting the GPs' pricing were high utilisation and contractual risk. Minor risks noted were input costs, community and organisational risks.
Table 3. Effect of the three scenarios of capitation fee on after-income tax of GPs

\begin{tabular}{llll}
\hline & \multicolumn{3}{c}{ Capitation fee } \\
\cline { 2 - 4 } & R2 000 000 & R4 030 000 & R5 000 000 \\
\hline Expenditure & R2 209 665 & R2 209 665 & R2 209 665 \\
$\quad$ Staff & R1 301 784 & R1 301 784 & R1 301 784 \\
Operating & R206 164 & R206 164 & R206 164 \\
$\quad$ Investments & R701 717 & R701 717 & R701 717 \\
$\quad$ Tax @ 40\% & -R83 866 & R728 134 & R1 116 134 \\
Net profit & -R125 799 & R1 092 201 & R1 674 201 \\
$\begin{array}{l}\text { Net profit change } \\
\text { for GP }\end{array}$ & $-116 \%$ & $37 \%$ & 109\%
\end{tabular}

\section{High utilisation}

GPs were concerned with consumer moral hazard - patients consulting for trivial reasons because it is free. We used three visits per person per annum as the utilisation rate for the NHI capitation, but if these were increased to four it would make the cost R523 per person per year for the public service and R536 per person per year for GPs. Optimal utilisation in the framework of well-structured continuity of care needs to be investigated. One GP felt that patients would overuse services and suggested patient co-payments, although there is evidence that incentives for the provider are more powerful for containing costs. ${ }^{7}$

There are problems in managing the balance of moral hazard by consumer and doctor. Doctors can act as principal agents for patients, but as with all agencies, there are imperfections. Medical care suffers from uncertainty and asymmetry of information, so demand can be fuzzy. Over-servicing in the fee-for-service mode can shift to underservicing in the capitation mode. Doctors will have to be challenged to synthesise social justice and industrial efficiency to ethically balance demand and supply. ${ }^{6}$ Any future contract with GPs must address utilisation in the framework of measurable patient satisfaction and clinical outcomes. Utilisation risk, beyond socio-economic, age and gender profiles, is likely to be adjusted for progressively as more morbidity data are collected in the NHI.

\section{Contractual risk}

There are severe weaknesses in the management of the district health services (DHS). Despite the opportunity to retool the DHS managerially and improve public service PHC, there is little evidence that this is being embarked upon. ${ }^{8}$ The size of the public services problems and the intention to contract at sub-national level raise

Table 2. Profile of adjusted and total expenses

\begin{tabular}{llll}
\hline & \multicolumn{1}{c}{ Adjustment proposed } \\
\hline Current turnover & R1 500588 & & \\
Current income & R799 282 & & \\
All expenses & R701 717 & $\rightarrow 560 \%$ more & R1 301784 \\
Staffing expenses & R 197323 & $\rightarrow 100 \%$ more & R 206164 \\
Operational expenses & R 206164 & $\rightarrow$ Variable & R 701717 \\
Other expenses (tax) & R 298230 & $\rightarrow 100 \%$ all expenses & R2 209665 \\
Investment costs & & &
\end{tabular}


questions about the capacity to manage. GPs expressed concerns about the capacity of government to pay on time.

Basic contractual parameters must be set (dealing with obvious abuse) to avoid perverse incentives and to incentivise practices financially to ensure an adequately competitive market. The contract must strengthen user power and allow choice of provider. Availability of doctors in rural areas is limited, hence the limited user choices and poor redress by managers. Rural areas may need large contract adjustments to attract more doctors.

In the UK, the National Health Service specifies minimal criteria regarding its contract with GPs. Professional autonomy is strong with few review systems or expectations. ${ }^{9}$ While it has recently changed, with some additional performance requirements, it remains a simple formula with seven income streams: the global sum (for essential, additional services and staff, and normalised for population), quality and outcomes frameworks (as performancerelated payments), enhanced (extra) services, premises, IT and dispensing fees.

\section{Improved management}

GPs stressed improved management and employing and training more staff as key strategies. The need to rearrange roles is implicit, particularly with 3 - 4 additional staff and the high expected utilisation rates. The respondents acknowledged that their role needed to change from being direct providers to being consultants, and shifting tasks to nurses. Non-doctors can lead $70 \%$ of consultations and much PHC can be nurse-led, with doctors as consultants in their own organisations..$^{10}$ However, there appeared to be reluctance to change roles and concerns about whether this would be effective. There were obvious concerns about the supply of human resources, especially PHC-trained nurses, with competition from government. GPs will require innovative thinking concerning organisational changes to build economies of scale., ${ }^{9,10}$ There were innovative suggestions around virtual practices and multidisciplinary teams as potentially more valuable than doctor practice groups.

Good management includes patient education and empowerment. ${ }^{11}$ Quality PHC requires that the team acts as gate-keeper, manages patients continuously, is comprehensive, and seeks to integrate and co-ordinate care. GPs felt that strong preventive activity was required in their practices, which bodes well for the quality of care and the embrace of strong community-based services envisaged in PHC re-engineering under NHI. Any contracting needs to enhance this approach.

\section{Conclusion}

$\mathrm{NHI}$ is only a funding mechanism and not a general panacea for South African healthcare - delivery is essential and will need careful examination in the existing South African context of poor public health systems. If GPs become incorporated into the health workforce with NHI this would remarkably alter the human resources available and enable GPs to become key drivers of the operational plans of the Department of Health. This may also allow the public service to focus on its stewardship role - strengthening priority programmes, community participation and inter-sectoral action.

This study has limitations in terms of the low response rate, potential bias of Internet access that was required, and our assumptions around risk pools and utilisation rates. It nonetheless offers a useful bottomup costing approach to an important segment within a broader NHI system. A key to the success of the long-planned initiative is merging improved access to healthcare with a strong foundation of preventive and promotive healthcare. This can be handled to a large extent by GPs incentivised and empowered to work in teams.

Acknowledgement. The contribution of Ayesha Moosa is gratefully acknowledged.

\section{References}

1. National Department of Health. National Health Insurance in South Africa. Pretoria: Department of Health, 2011

2. Light DW. Historical and comparative reflections on the US national health insurance reforms. Soc Sci Med 2011;72:129-132. [http://dx.doi.org/10.1016/j.socscimed.2010.10.015]

3. McLeod H. IMSA NHI Policy Brief 11 - Estimating delivery efficiency under NHI. 2010. http://www imsa.org.za/national_health_insurance_policybrief_11_0.html. (accessed 23 December 2010). 4. McLeod H. IMSA NHI Policy Brief 10 - Defining the benefit package. 2010. http://www.imsa.org.za/ national_health_insurance_policybrief_10_0.html (accessed 23 December 2010).

5. Council for Medical Schemes. Annual Report 2009/2010. Pretoria: Council for Medical Schemes, 2010 6. Schoen C, Osborn R, Huynh PT, Doty M, Peugh J, Zapert K.. On the front lines of care: primary car doctors' office systems, experiences, and views in seven countries. Health Affairs 2006;25:555. [http:// dx.doi.org/10.1377/hlthaff.25.w555

. Chernew M. Bundled payment systems: Can they be more successful this time. Health Services Research 2010;45:1141-1147. [http://dx.doi.org/10.1111/j.1475-6773.2010.01173.x]

8. Harrison D. An overview of health and health care in South Africa 1994-2010: Priorities, progres and prospects for new gains. A discussion document commissioned by the Henry J. Kaiser Family Foundation to help inform the national health leaders retreat, Muldersdrift, 2010. http://www. bhfglobal.com/files/bhf/overview1994-2010.pdf (accessed 23 December 2010).

9. Pollock A, Price D. Privatising primary care. Br J Gen Pract 2006;56:565. [PMCID: PMC1874517]

10. Laurant M, Reeves D, Hermens R, Braspenning J, Grol R, Sibbald B. Substitution of doctors by nurses in primary care (Review). The Cochrane Library, Issue 4, 2010. Oxford: Update Software. [http:// dx.doi.org/10.1002/14651858.CD001271.pub2]

11. McIntyre D. Private sector involvement in funding and providing health services in South Africicis Implications for equity and access to health care. EQUINET, Harare: Health Economics Unit, 2010.

Accepted 30 July 2012 